\title{
Comparative genomic analysis of driver mutations in matched primary and recurrent meningiomas
}

\author{
Joshua Loewenstern ${ }^{1}$, John Rutland ${ }^{1}$, Corey Gill ${ }^{1}$, Hanane Arib ${ }^{2}$, Margaret Pain ${ }^{1}$, \\ Melissa Umphlett ${ }^{3}$, Yayoi Kinoshita ${ }^{3}$, Russell McBride ${ }^{3}$, Michael Donovan $^{3}$, Robert \\ Sebra ${ }^{2}$, Joshua Bederson ${ }^{1}$, Mary Fowkes ${ }^{3}$ and Raj Shrivastava ${ }^{1,4}$ \\ ${ }^{1}$ Department of Neurosurgery, Icahn School of Medicine at Mount Sinai, NY, New York, USA \\ ${ }^{2}$ Department of Genetics and Genomic Sciences, Icahn School of Medicine at Mount Sinai, NY, New York, USA \\ ${ }^{3}$ Department of Pathology, Icahn School of Medicine at Mount Sinai, NY, New York, USA \\ ${ }^{4}$ Department of Otolaryngology, Icahn School of Medicine at Mount Sinai, NY, New York, USA \\ Correspondence to: Joshua Loewenstern, email: joshua.loewenstern@icahn.mssm.edu \\ Keywords: meningioma; tumor recurrence; genomics; driver mutation; progression-free survival \\ Received: February 09, $2019 \quad$ Accepted: April 21, 2019 Published: May 28, 2019 \\ Copyright: Loewenstern et al. This is an open-access article distributed under the terms of the Creative Commons Attribution Li- \\ cense 3.0 (CC BY 3.0), which permits unrestricted use, distribution, and reproduction in any medium, provided the original author \\ and source are credited.
}

\section{ABSTRACT}

A significant proportion of low-grade WHO grade I and higher-grade WHO grade II or III meningiomas are at risk to develop post-resection recurrence. Though recent studies investigated genomic alterations within histological subtypes of meningiomas, few have compared genomic profiles of primary meningiomas matched to their recurrences. The present study aimed to identify oncogenic driver mutations that may indicate risk of meningioma recurrence and aggressive clinical course. Seventeen patients treated for low-grade $(n=8)$ or high-grade $(n=9)$ meningioma and underwent both primary and recurrent resection between 2007-2017 were reviewed. Tumor specimens $(n=38)$ underwent genomic sequencing of known oncogenic driver mutations. Primary and recurrent tumors were compared using matchedpair analyses for mutational associations with clinical outcomes including functional status, progression-free survival (PFS) and overall survival (OS). Most common driver mutations included POLE and NF2. There was no enrichment for any driver mutation from primary to recurrent tumor specimen. NF2 mutant meningiomas were associated with larger tumor size (8-fold increase), presence of vasogenic edema, and higher mitotic proliferation on univariate and independently on multivariate regression ( $p$ 's < 0.05) after controlling for preoperative and tumor features. Tumors with POLE driver mutations were associated with decreased functional status at last postoperative follow-up $(p=0.022)$ relative to presentation. Mutation status was not associated with PFS or OS on multivariate Cox regression, but rather with grade of resection $(p=0.046)$ for PFS. While primary and recurrent tumors exhibited similar driver mutations within patients, the identification of driver mutations associated with clinical outcomes is crucial for guiding potential targeted treatments in recurrent meningiomas.

\section{INTRODUCTION}

Meningiomas are the most common primary brain tumor, accounting for approximately $34 \%$ of all primary intracranial neoplasms. While the majority of meningiomas are classified as WHO grade I and are benign, approximately $20 \%$ are grade II (atypical) and grade III (anaplastic). Grade II meningiomas account for 5-15\% of all meningiomas, can exhibit atypical histological features that include prominent nucleoli, hypercellularity, necrosis, high nuclear-to-cytoplasmic ratio, or brain invasion [1]. Grade II meningiomas are more likely to grow more rapidly than benign meningiomas and have a greater likelihood of recurring following gross total resection. 
Adjuvant radiation therapy (RT) is often prescribed in the case of subtotal resection of Grade II meningiomas. Grade III meningiomas comprise the smallest proportion of cases, about $1-3 \%$, and have poor oncological outcomes. Grade III meningiomas grow at a faster rate than both benign and atypical tumors and are more likely to invade brain tissue, metastasize to other organs, and recur than the Grades I and II meningiomas [2, 3].

Diagnosis of grade II and III meningiomas can manifest heterogeneous clinical outcomes [2, 4]. Reports of 5-year progression free survival rates for combined Grades II and III meningiomas after radical resection range from $20 \%-50 \%[2,4]$, reinforcing the highly variable longterm results for these tumors. Current markers of improved prognosis are poorly defined in the literature and cannot account fully for this divergence in individual clinical behaviors of atypical and malignant meningiomas, making treatment prediction and the decision for aggressive multimodal therapy difficult. Indeed, the current WHO grading system relies on histopathological features and is often imprecise and insensitive to predict long-term oncologic outcomes such as recurrence and survival.

Recently, there has been increased interest in elucidating how genomic alterations may inform treatment stratification in intracranial tumors $[5,6]$. There is a critical need to better understand genomic alterations that are associated disease outcomes such as tumor recurrence, response to radiotherapy, and survival. Meningiomas that are incompletely resected due to anatomical location or are grade II or III have increased risk of recurrence. In these cases, adjuvant radiotherapy is commonly used to target the surgical bed and has been shown to improve local control [7] and survival $[8,9]$. However, the utility of the wait-and-see strategy for treating meningioma is debated and is currently being investigated by the NCT03180268 and ROAM/EORTC-1308 trials [10, 11]. Therefore, identifying genomic markers that may be associated with treatment resistance or contribute to meningioma recurrence is important.

Prior studies have established compelling evidence for the role of genomic characterization in meningioma pathogenesis. The tumor suppressor gene, neurofibromin 2 (NF2), is well studied in the context of meningioma. Mutations in NF2 have been associated with the development of benign intracranial tumors, including schwannomas and meningiomas [12, 13]. Recently, alterations in other oncogenic genes such as TRAF7, $A K T 1, K L F 4, P I K 3 C A, S M O$, and DMD have also been implicated in meningioma etiology $[14,15]$. In their review of 553 meningiomas, Yuzawa et al reported $N F 2$, TRAF7, AKT1, KLF4, PIK3CA, and SMO mutations in 55, $20,9,9,4.5$, and $3 \%$ of tumors [16].

Others have sought to identify genomic determinates of meningioma aggression. Bi et al observed that PIK3CA and Hedgehog pathway mutations were indicative of low-grade meningiomas, whereas NF2 mutation and widespread genomic alterations were characteristic of high-grade tumors [17, 18]. Additionally, the promoter region of the gene that encodes the reverse transcriptase component of telomerase (TERT), has also been implicated in meningioma behavior.

Despite these findings, there has been limited success in identifying how mutation status may influence treatment outcomes. Further, only one prior study has compared mutation status from primary meningioma to subsequent recurrence(s) [19]. The focus of this study aims to characterize the genomic profiles of matched primary and recurrent meningiomas in 17 patients and associate mutation status with critical treatment outcomes including recurrence, functionality, and survival.

\section{RESULTS}

\section{Patient and tumor characteristics}

Demographic and tumor features along with mutation status among paired primary and recurrent meningiomas are depicted in Figure 1. The overall sample consisted of a majority of females $(65 \%)$ with an average age of 61 years $(\mathrm{SD}=11.6$ years $)$ on initial presentation. Patients did not differ in their preoperative functional status from primary to recurrent tumor $(p=0.13)$. Most meningiomas were located in skull base regions $(71 \%)$, followed by convexity, parasagittal, or falcine regions $(24 \%)$, and 1 was located in a spinal region (see Table 1$)$. Median tumor volume was $3.5 \mathrm{~cm}^{3}\left(\mathrm{IQR}=0.9-11.8 \mathrm{~cm}^{3}\right)$ and was significantly larger for primary tumors compared to their matched recurrences (4.7 vs. $1.7 \mathrm{~cm}^{3}, p=0.019$ ). A minority of primary and recurrent tumors presented with associated vasogenic edema ( 29 vs. $24 \%, p>0.99$ ). The majority of tumors were completely resected (84\%), which did not differ from primary to recurrence $(p=0.34)$.

Eight $(47 \%)$ patients had recurrent WHO grade I meningiomas and 9 (53\%) had recurrent atypical WHO grade II meningiomas. No matched pairs of anaplastic WHO grade III meningiomas were encountered in our cohort. Of the WHO grade I meningiomas, 12 (75\%) were meningothelial subtype, 2 fibroblastic, and 2 psammomatous. Within the WHO grade II specimens, the majority (91\%) were atypical subtype and 2 were clear cell. On histopathological examination, brain invasion was noted in a minority of tumors (13\%). Mean mitotic index did not differ from primary tumor to recurrence (2.47 vs. 2.29 per $10 \mathrm{HPF}, p=0.75)$. Ki67 labeling similarly did not statistically differ for those cases with Ki67 labeling (32\%).

\section{Genomic profiles}

Most common driver mutations are depicted by matched pairs in Figure 1. NF2 and POLE driver mutations were each present in $13(34 \%)$ and $12(32 \%)$ of the 38 total primary and recurrent tumor samples, 
respectively. $C D K N 2 A, A R I D 1 A, B R C A 1, N F 1$, and $A K T 1$ were also commonly identified in meningioma samples across the cohort. Other driver mutations identified in one or two tumors (30 other genes identified, see Supplementary Figure 1) included NOTCH3, SMO, $P I K 3 C A$, and BRCA2. Of note, no driver mutations in the paired cohort were identified for TERT, SMARCB1, or $B A P 1$. There were no differences by presence of a specific driver mutation in regard to patient sex, location of tumor, or grade of resection. Patients with an NF2 mutant tumor were on average older than those without the mutation (66.5 vs. 56.8 years, $p=0.010$ ). There was also no difference between primary tumors and their recurrences regarding tumors with multiple driver mutations (47 vs. $53 \%, p>0.99$ ) or median number of total driver mutations $(p>0.99$, Table 1$)$.

\section{Associations with tumor features}

Several driver mutations were found to be associated with specific tumor features. AKT1 mutations were found in more WHO grade I tumors than higher grade meningiomas $(p=0.020)$. Additionally, NF2 mutation status was associated with several tumor features. A majority $(63.6 \%)$ of tumors presenting with vasogenic edema on preoperative imaging had an NF2 driver mutation compared to $22.2 \%$ of tumors without edema $(p=0.020)$. On multivariate regression, the presence of an $N F 2$ mutation was found to be an independent predictor of larger tumor volume $($ Beta $=19.8, p=0.008$, see Table 2$)$, controlling for other preoperative patient characteristics and tumor features. Median tumor volume with the mutation was $14.3 \mathrm{~cm}^{3}\left(\mathrm{IQR}=3.7-47.2 \mathrm{~cm}^{3}\right)$ relative to $1.7 \mathrm{~cm}^{3}\left(\mathrm{IQR}=0.9-4.9 \mathrm{~cm}^{3}\right)$ without the mutation $(p=0.021)$, an over eight-fold increase in median tumor size. Figure 2 depicts a representative patient with a large primary tumor harboring an $N F 2$ driver mutation with vasogenic edema prior to initial resection compared with the patient's recurrent tumor also presenting with substantial vasogenic edema. Moreover, presence of an NF2 mutation was found to be an independent predictor of mitotic index on multivariate regression analysis (beta=3.0, $p=0.006$, Table 2). Mean mitotic index for $N F 2$ mutation positive tumors was 4.7 per $10 \mathrm{HPF}$ $(\mathrm{SD}=5.4)$ compared to $1.5(\mathrm{SD}=2.3)$ without the mutation $(p=0.014)$.

\section{Associations with clinical outcomes}

The median time for patients to develop a meningioma recurrence after primary tumor resection was 7.0 months (IQR=3.5 to 18.0 months). The present analysis did not find any association with time to recurrence for any specific driver mutation. The only factor found to be associated with timing of recurrence on multivariate Cox regression analysis, with preoperative patient characteristics and tumor features entered as covariates, was Simpson grade of resection at primary resection such that tumors with a subtotal resection were more likely to progress in less time than those with a complete resection $(\mathrm{HR}=3.88, p=0.046$, see Table 2).

At initial postoperative follow-up and last followup examination, patients did not differ in median functional status from their primary meningioma to their recurrence ( $p=0.36$ and $>0.99$, respectively, see Table 1$)$. Further, there was no difference within matched pairs in the proportion of patients that decreased in functional status at their initial follow-up or last follow-up relative

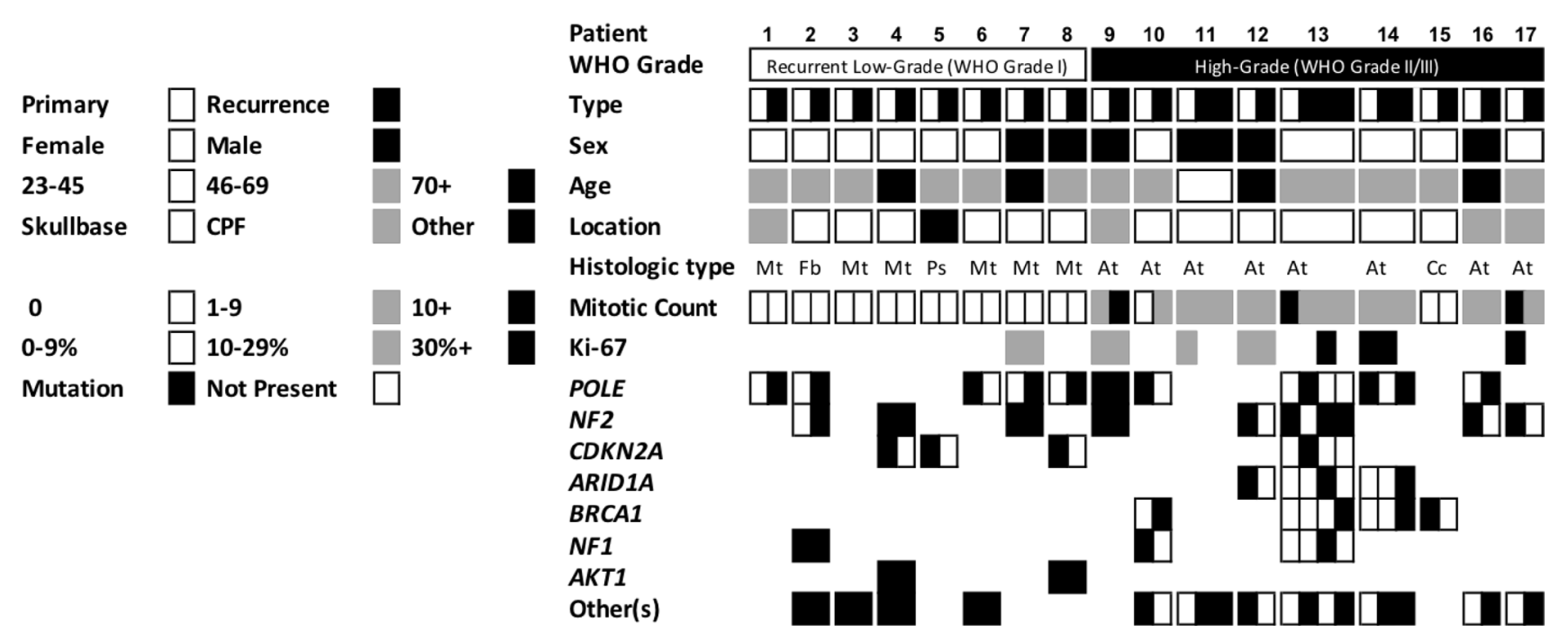

Figure 1: Demographics, tumor features, and mutation status of the cohort of 17 patients with matched targeted sequenced primary and recurrent meningioma. The seven most common driver mutations of the cohort are depicted. Each tumor was analyzed separately for presence of driver mutations. Abbreviations: CPF, convexity, parasagittal, or falcine; other, spinal; Mt, meningothelial; Fb, fibroblastic; Ps, psammomatous; At, atypical; Cc, clear cell. 
Table 1: Preoperative and tumor characteristics of matched primary tumors to first recurrence $(17$ pairs $=34$ tumors $)$

\begin{tabular}{|c|c|c|c|}
\hline & Primary $(n=17)$ & Recurrence $(n=17)$ & $P$-value \\
\hline Variable & $N(\%)$ or Median (IQR) & $N(\%)$ or Median (IQR) & \\
\hline \multicolumn{4}{|l|}{ Clinical Features } \\
\hline Preop Functional Status (KPS) & $70(70-80)$ & $80(70-90)$ & 0.13 \\
\hline Tumor Location & & & $>0.99$ \\
\hline Skull base & $12(70.6)$ & $12(70.6)$ & \\
\hline$C P F$ & $4(23.5)$ & $4(23.5)$ & \\
\hline Other & $1(5.9)$ & $1(5.9)$ & \\
\hline Tumor Volume $\left(\mathrm{cm}^{3}\right)$ & $4.7(1.1-31.2)$ & $1.7(0.6-7.3)$ & 0.019 \\
\hline Presence of Vasogenic Edema & & & $>0.99$ \\
\hline Yes & $5(29.4)$ & $4(23.5)$ & \\
\hline No & $12(70.6)$ & $13(76.5)$ & \\
\hline Simpson Grade & & & 0.34 \\
\hline Gross Total (1-3) & $13(76.5)$ & $16(94.1)$ & \\
\hline Subtotal (4-5) & $4(23.5)$ & $1(5.9)$ & \\
\hline Presence of Brain Invasion & & & $>0.99$ \\
\hline Yes & $2(11.8)$ & $2(11.8)$ & \\
\hline No & $15(88.2)$ & $15(88.2)$ & \\
\hline WHO Grade & & & $>0.99$ \\
\hline I & $8(47.1)$ & $8(47.1)$ & \\
\hline II & $9(52.9)$ & $9(52.9)$ & \\
\hline III & $0(0.0)$ & $0(0.0)$ & \\
\hline Mitotic Index [Mean (SD)] & $2.47(4.6)$ & $2.29(3.3)$ & 0.75 \\
\hline$\geq 4$ per $10 \mathrm{HPF}$ & $5(29.4)$ & $5(29.4)$ & $>0.99$ \\
\hline Ki67/MIB-1 (\%) & $22.5(20-28.8)$ & $20(16.3-27.5)$ & 0.77 \\
\hline \multicolumn{4}{|l|}{ Genomics } \\
\hline Multiple $(\geq 2)$ Driver Mutations & $8(47.1)$ & $9(52.9)$ & $>0.99$ \\
\hline Total Driver Mutations & $1(1-2)$ & $1(1-2)$ & $>0.99$ \\
\hline \multicolumn{4}{|l|}{ Outcomes } \\
\hline Postop Functional Status (KPS) & $80(75-90)$ & $80(70-95)$ & 0.36 \\
\hline Decreased KPS relative to Preop & $2(11.8)$ & $3(17.6)$ & 0.48 \\
\hline Functional Status at last follow-up (KPS) & $80(65-90)$ & $80(65-90)$ & $>0.99$ \\
\hline Decreased KPS relative to Preop & $5(29.4)$ & $6(35.3)$ & $>0.99$ \\
\hline
\end{tabular}

Abbreviations: KPS, Karnofsky Perfornance Status; CPF, convexity, parasagittal, or falcine.

"Ki-67/MIB-1 available for 11 (32.4\%) tumors.

Values represent $N(\%)$ or Median (IQR), as appropriate, unless otherwise specified. Compared matched pairs with McNemar's test for paired proportions or Wilcoxon signed-rank test.

to preoperative functional status $(p=0.48$ and $>0.99$, respectively).

Half of the patients underwent adjuvant RT after either primary or recurrent tumor resection. Two $(22 \%)$ radiation treatments occurred shortly after primary resection, while the remaining 7 patients $(78 \%)$ were not irradiated until after the recurrent tumor resection. Use of adjuvant RT correlated with wildtype $N F 2$ status $(p=0.020)$. As of the completion of this study, $12(71 \%)$ patients were alive, $3(18 \%)$ were dead, and 2 were lost 
Table 2: Multivariate regression analyses on tumor volume and mitotic index and Cox multivariate regression analyses on progression-free survival (PFS) and overall survival (OS)

\begin{tabular}{|c|c|c|c|c|}
\hline \multirow[t]{2}{*}{ Characteristic } & \multicolumn{3}{|c|}{ Multivariate on Tumor Volume } & \multirow[b]{2}{*}{$P$-value } \\
\hline & Beta & SE & $95 \%$ CI & \\
\hline \multirow[t]{3}{*}{ NF2 mutation } & 19.8 & 7.0 & $5.6-34.0$ & 0.008 \\
\hline & \multicolumn{3}{|c|}{ Multivariate on Mitotic Index } & \\
\hline & Beta & SE & $95 \%$ CI & $P$-value \\
\hline WHO Grade & 4.3 & 1.0 & $2.3-6.3$ & $<0.001$ \\
\hline \multirow[t]{3}{*}{ NF2 mutation } & 3.0 & 1.0 & $0.9-5.0$ & 0.006 \\
\hline & \multicolumn{4}{|c|}{ Cox Multivariate on Progression-Free Survival } \\
\hline & HR & $95 \% \mathrm{CI}$ & $P$-value & \\
\hline \multirow[t]{3}{*}{ Simpson grade of resection } & 3.88 & $1.02-14.7$ & 0.046 & \\
\hline & \multicolumn{3}{|c|}{ Cox Multivariate on Overall Survival } & \\
\hline & HR & $95 \% \mathrm{CI}$ & $P$-value & \\
\hline Preop Functional Status (KPS) & 0.83 & $0.66-1.05$ & 0.095 & \\
\hline
\end{tabular}

Abbreviations: SE, standard error; HR, hazard ratio; CI, confidence interval; KPS, Karnofsky Performance Status.

Preoperative clinical, demographic, and tumor features were entered into each model. Significant variables are shown only.
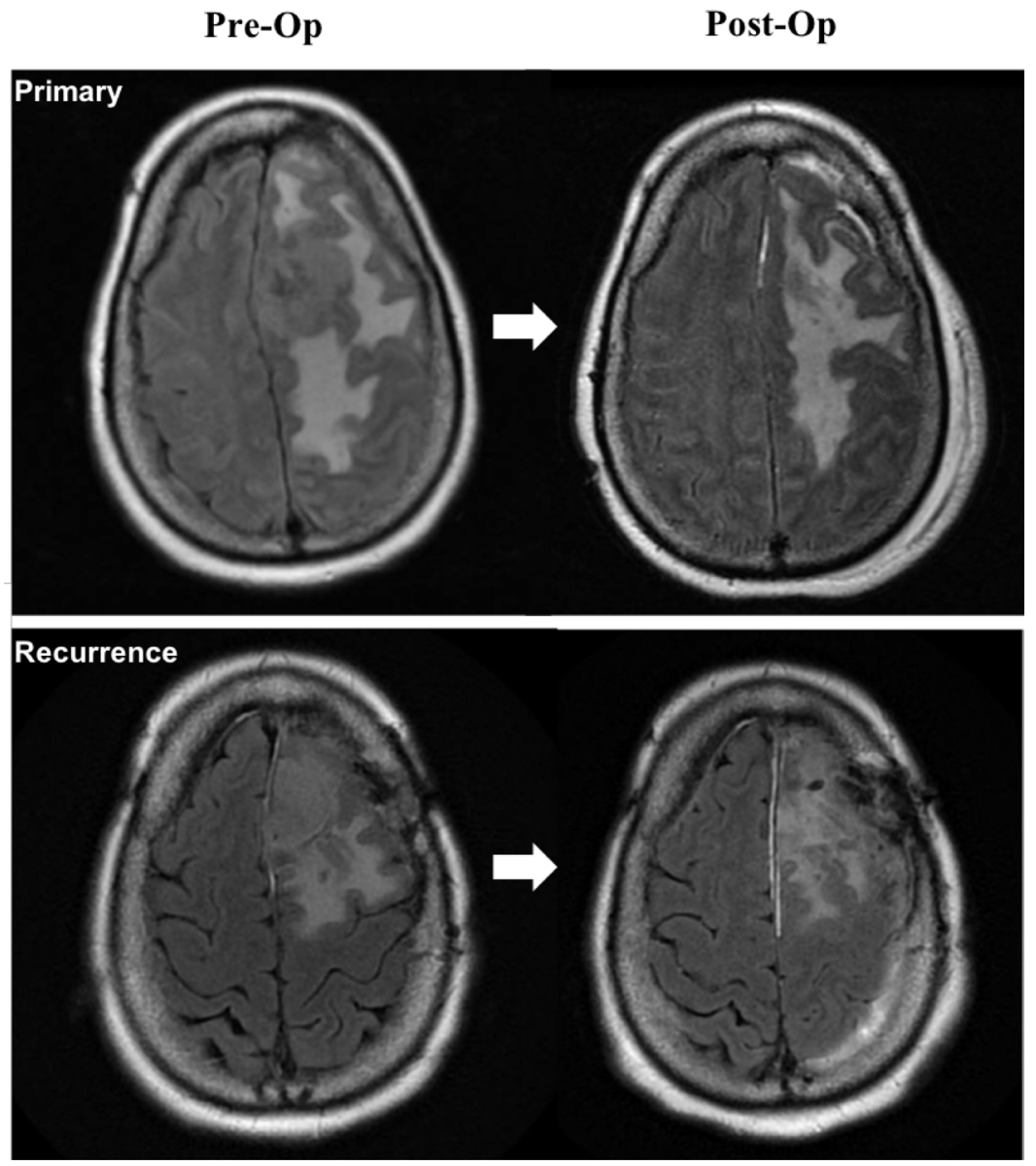

Figure 2: T2 FLAIR magnetic resonance (MR) imaging of a representative patient with an NF2 mutation positive WHO grade II meningioma (frameshift deletion at locus chr22:30074229) showing large tumor volume with vasogenic edema for the primary tumor (top) and a recurrence (bottom). Left images depict preoperative MR imaging and right images are postoperative MR imaging. Recurrent meningioma was found to have an ARIDIA nonsense mutation at locus chr1:27101099 in addition to the NF2 frameshift deletion. 
to follow-up. The overall median observation time for patients was 49.5 months (IQR=34.1 to 81.2 months). The present study did not find any significant independent predictors of risk for mortality on Cox regression analysis (Table 2).

\section{DISCUSSION}

In a single-center analysis of matched tumor specimens of 17 patients who underwent primary and recurrent meningioma resection during over a 10 -year period, we aimed to compare mutation status in determining significant predictors of tumor recurrence, survival, and other clinical outcomes. Though matched primary and recurrent tumors shared similar driver mutations as expected, genomic analysis revealed key associations among mutations and tumor features and clinical outcomes, particularly involving the NF2 gene.

\section{Preoperative presentation and tumor features}

Matched primary and recurrent meningiomas differed only in tumor size among preoperative and tumor features (Table 1), which is likely due to serial follow-up imaging and neurologic exams aimed to detect recurrent tumors before presentation of clinical sequelae. However, there were notably no differences on the whole between primary and recurrent tumors in regard to affecting presenting functional status or specific tumor features including vasogenic edema, brain invasion, or proliferation index. Given that WHO grade remained constant between primary tumor and recurrence, it is not surprising that tumor proliferation and behavior were similar, though a larger sample may better characterize such differences [1].

After targeted sequencing for clinically actionable driver mutations, the most common identified were $N F 2$ and POLE. A total of 13 primary or recurrent specimens (34\%) were NF2 mutation positive, which is consistent with prior genetic investigations that have cited sporadic NF2 mutations in up to half of studied meningiomas $[16,17,20]$. For example, Yuzawa et al. reported an NF2 mutation in $55 \%$ of meningiomas reviewed in a large sample while Bi et al. similarly found NF2 mutations in $53 \%$ of their meningioma sample $[16,17]$. POLE variants, which were also present in 12 tumors $(32 \%)$ in the sample and encode for the catalytic subunit of DNA polymerase epsilon, have not commonly been identified in prior meningioma genomic studies, but have been implicated in syndromes related to neurofibromatosis type 1 [21]. Other common driver mutations in our cohort such as $C D K N 2 A$, ARID1A, BRCA1, NF1, AKT1, SMO, PIK3CA (see Figure 1 and Supplementary Figure 1) have similarly been noted in various prior sequencing studies of meningiomas $[13,16,17,22-26]$.

Of note, other common genetic variants identified in prior studies including TERT, SMARCB1, and BAP1 were examined as part of the panel, but not identified as driver mutations in the current sample cohort. While the present analysis did not identify driver mutations within the TERT gene, our technique did not evaluate the TERT promoter region which, through effects on telomerase expression, has been linked to meningioma recurrence and survival in a number of past studies [15, 26-32]. However, Juratli et al. has also demonstrated variant rearrangements within the TERT genetic region within a sample of treatment-resistant high grade meningiomas, which was not replicated in our sample of matched tumors [27]. SMARCB1 mutations, involved in gene expression regulation and also located in close proximity to $N F 2$ on chromosome 22 , have also been identified in particularly atypical meningiomas in prior work, but were not identified in our matched tumor pairs [33-35]. Similarly, TRAF7 and KLF4 mutations have been linked to meningioma $[14,16,33]$, but were not assessed by the panel of the present study. As TRAF7 mutations were found in up to a quarter of meningiomas in prior studies, particularly in secretory meningiomas $[14,33]$, such mutations would likely have been present in our matched tumor pairs. Recently, $D M D$ inactivation was linked to risk of mortality [15], but similarly was not assessed in the present clinically actionable driver mutation-targeted study.

Further, we did not find any differences between primary and recurrent tumors by specific driver mutation in regard to baseline characteristics (e.g., sex, location, grade of resection), though previous work has noted, for example, a tendency for non-NF2 variant tumors such as $A K T 1$ and $S M O$ to develop in skull base regions relative to $\mathrm{CPF}$ regions $[25,33,36]$. However, several driver mutations were associated with specific tumor features including WHO grade. For example, tumors with an $A K T 1$ driver mutation tended to be low-grade.

\section{Role of NF2 mutations}

NF2 mutations were found to be significantly associated with several tumor features and patient characteristics. Patients with NF2 mutant meningiomas were on average 10 years older than patients without an $N F 2$ mutation, suggesting that NF2-driven meningiomas may display a slower growing, more indolent disease course. Additionally, NF2 mutation was significantly associated with larger tumor volume. This may also indicate that meningiomas driven by $N F 2$ mutations are slower growing and only become symptomatic when they become very large and cause mass effect on surrounding structures. Receiver operating characteristic (ROC) curve depicting tumor volume by NF2 mutational status is shown in Figure 3. At a tumor volume of greater than or equal to $3.5 \mathrm{~cm}^{3}$ on preoperative MRI, volume predicted $N F 2$ mutational status with a sensitivity of $76.9 \%$, specificity of $63.0 \%$, positive predictive value (PPV) of $50.0 \%$, and negative predictive value (NPV) of $85.0 \%$. Thus, finding a 
small tumor volume on preoperative imaging may be a fair indicator of non-NF2 mutational status, but larger cohorts are needed to support this finding.

Tumor volume may have also mediated the increased vasogenic edema observed in tumors with NF2 mutation. Vasogenic cerebral edema is a type of extracellular edema that occurs when the tight junctions of the blood brain barrier is disrupted, and results in leakage of fluids from capillaries into the interstitial brain compartment. Morimoto et al. reported significant correlation between tumor volume and degree of peritumoral edema in intracranial meningiomas, suggesting that larger tumors may cause greater edema [37].

Additionally, merlin, the NF2-encoded protein, may play a role in stabilizing intercellular junctions in the blood brain barrier, so vasogenic edema may be mediated through absence of this gene product [32]. NF2 is a tumor suppressor gene that is located on the long arm of chromosome $22 \mathrm{q} 12$, and was the first single-gene mutation to be linked with risk of developing meningioma $[38,39]$. Merlin, which is responsible for a number of inhibitory cellular functions including Rac-PAK pathway suppression [40, 41], inhibition of the PI3K-Akt pathway [42], and suppression of the EGFR-Ras-ERK pathway [43]. Merlin's inhibitory functions promote contact inhibition and suppress mitotic signaling at cellular junctions [40]. While $N F 2$ mutation-driven meningiomas have been shown to differ from non-NF2 mutation-driven meningiomas with regard to histological subtype and intracranial location [44], the phenotypic and oncological features of meningiomas driven by $N F 2$ mutation status remain inadequately described.

Moreover, the findings also suggest that NF2-driven meningiomas may exhibit a more indolent course than non-NF2-driven meningiomas. Because subtotal resection is the most common indication for postoperative RT, and tumors with $N F 2$ mutations received less adjuvant RT, it is also possible that $N F 2$ mutation-driven meningiomas are easier to resect, due to surgical access of their specific intracranial location. In the present study, $8 \%$ of meningiomas with $N F 2$ mutations were subtotally resected compared with $19 \%$ of non-NF2-driven meningiomas. While this effect was not significant, larger studies are needed to determine whether $N F 2$ mutation plays a role in extent of resection.

Taken together, these findings suggest that $N F 2$ mutant meningiomas tend to be slower growing, more indolent tumors than meningiomas harboring other genomic alterations. Interestingly, the incidence of $N F 2$ mutations is fairly proportional among WHO grades. This finding suggests that $N F 2$ mutation is involved in an early initiation event in meningioma tumorigenesis as opposed to tumor progression [45]. However, genomic alterations in atypical and anaplastic meningiomas are multifactorial, involving numerous genetic changes, and the role of NF2 in tumor progression requires further investigation. Implications of $N F 2$ mutations significantly influencing meningioma progression have prompted clinical trial investigations of inhibition of focal adhesion kinase, thought to be associated with $N F 2 /$ merlin-mediated tumor

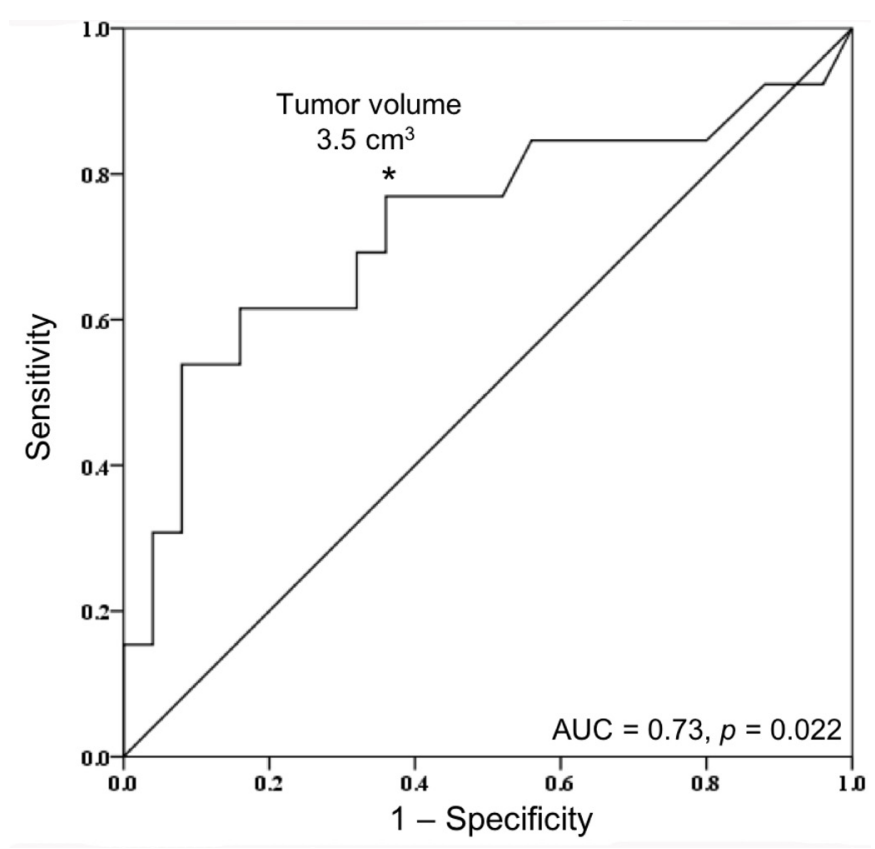

Figure 3: Receiver operating characteristic (ROC) curve of tumor volume by NF2 mutational status. Area under the curve (AUC) was equal to $0.73(p=0.022)$. ${ }^{*}$ At a tumor volume of greater than or equal to $3.5 \mathrm{~cm}^{3}$, sensitivity and specificity for predicting NF2 mutational status was $76.9 \%$ and $63.0 \%$, respectively. Positive predictive value (PPV) and negative predictive value (NPV) was $52.6 \%$ and $84.2 \%$, respectively. 
growth $[11,22]$. Execution of high throughput genomic analysis in large multi-center studies are needed to further elucidate the role of $N F 2$ within the complex phenotypic manifestations of meningiomas.

\section{Genomic associations with clinical outcomes}

Among the recurrent meningiomas in this matched cohort, we did not find driver mutations to be associated with time to recurrence on univariate analysis, even though the median time to recurrence was 7.0 months, consistent with prior studies of meningioma recurrence. On multivariate Cox regression analysis, the only independent predictor of PFS was grade of resection such that a subtotal resection was associated with a higher risk of progression in relatively less time than a complete resection (see Table 2). Prior genomic studies, however, have linked the presence of an NF2 mutation to increased recurrence relative to other variant drivers $[16,17]$. For example, Yuzawa and colleagues reported 23\% of tumors with an NF2 mutation had a recurrence within the study follow-up period [16]. Moreover, NF2 mutations were recently shown to contribute to a decreased PFS in a sample of WHO grade I and II meningiomas [20]. In our sample, primary tumors with an NF2 mutation recurred in a mean of 14.5 months relative to 19.6 months for those without such a mutation, but this was not significant given the underpowered sample $(p=0.74)$. Kaplan-Meier plot of PFS for patients with and without an NF2 mutation is depicted in Figure 4. Though not investigated in this study, TERT promoter mutations have been demonstrated in prior work to be associated with unfavorable PFS across low- and high-grade meningioma [28, 29, 31]. Taken together, the findings suggest drivers for recurrence and tumor behavior are likely present in the primary tumor and are less likely, in the majority of cases, acquired mutations in residual tumor cells post-resection. However,

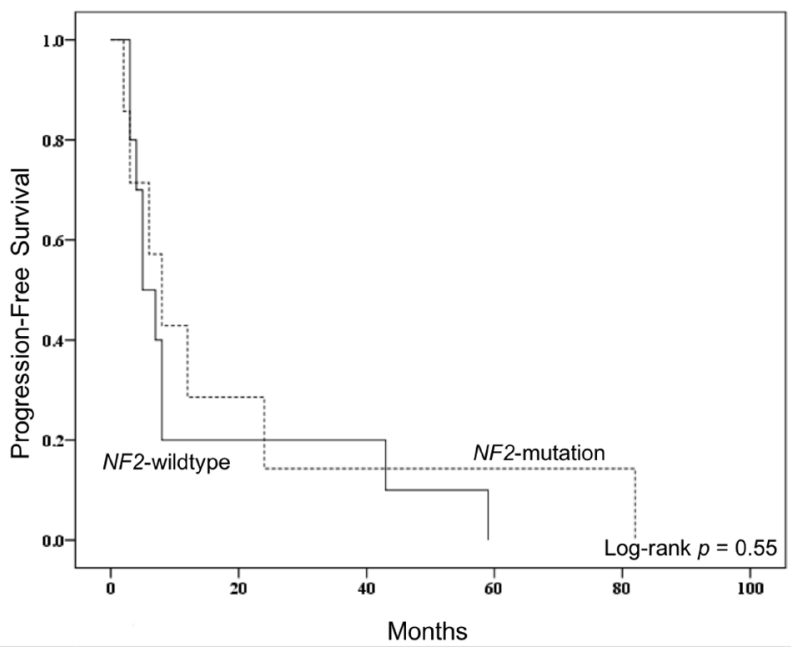

future studies should continue to investigate the genetic associations with tumor recurrence and, specifically, tumor subtypes in which acquired mutations may have a larger role in driving recurrence.

In regard to postoperative functional status, patients possessing primary or recurrent tumors with $P O L E$ driver mutations had decreased functional status post-resection compared to those patients without such genomic alterations. First, POLE, along with $N F 2$, was the most common encountered mutation in the matched pairs and was associated with decreased functionality at last followup. Though POLE mutations in higher-grade meningioma have only recently been reported in prior work [46], POLE mutations have been linked to worse prognosis in other cancers such as in particular subgroups of colorectal and endometrial cancer patients [47].

Lastly, on analysis of mortality risk, the present analysis did not uncover an association with any driver mutation with survival, including presence of an NF2 mutation (see Table 2 and Figure 4). Patients presenting with a severely symptomatic meningioma tend to have poorer outcomes post-resection, including a potential increased risk for mortality [48, 49]. While not identified within our matched tumor sample, prior genetics work have linked $C D K 2 N A$ mutations to decreased survival in anaplastic meningioma [50], and TERT promoter mutations to decreased OS in both higher grade meningioma [29] and across tumor grades [31]. Though the median follow-up time was over 4 years after initial resection, a larger cohort of patients with a longer follow-up time may reveal genetic associations with mortality risk.

\section{Limitations}

There were several limitations of the present study including its retrospective nature and associated biases in design. First, we limited our analysis to include only

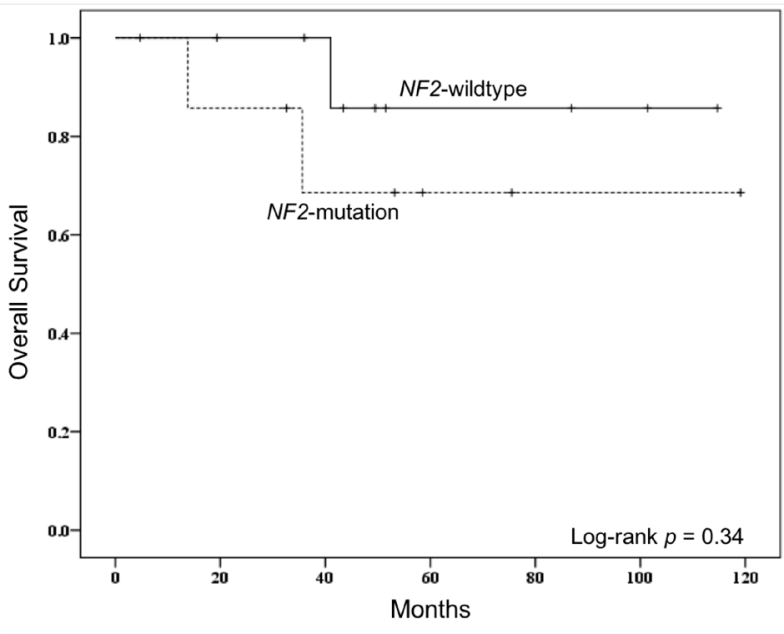

Figure 4: Kaplan-Meier progression-free survival (PFS) curve (left) and overall survival (OS) curve (right) for comparisons by NF2 mutational status. Comparisons were made by log-rank tests. 
patients with surgical resection of both a primary and recurrent meningioma at our medical center. Second, we did not perform sequencing to assess germline status from normal samples for each patient to control for germline variants. We therefore acknowledge that some of our identified variants may be germline in nature and not specific to the tumor. Third, our study utilized a targeted panel of oncogenic genes associated with cancer and did not include whole-exome or whole-genome sequencing. As such we were note able to assess gene status of several known meningioma-associated mutations nor the TERT promoter mutations. Fourth, we performed sequencing of only one specimen for each surgical resection, and thus we were note able to account for genomic heterogeneity that may underlie high-grade meningiomas. Such a limitation can likely account for why certain clonal driver mutations were not identified in both primary and recurrent specimens. Overall, the analysis was bounded by several clinical limitations and the interpretations were made from the best clinical information available.

\section{MATERIALS AND METHODS}

\section{Patient cohort}

We performed a search of our institutional database to identify patients, with available archived formalin fixed paraffin-embedded specimens (FFPE), who presented with a primary meningioma for resection and subsequently had a tumor recurrence additionally resected during a 10-year period from 2007 to 2017. The resulting cohort consisted of 17 patients with matched primary and recurrent tumor samples (see Figure 1 and Table 1). Three patients had more than two resections during this period. Patients who underwent a primary meningioma resection without subsequent recurrence during this period or underwent a recurrent meningioma resection without having received the primary resection at our medical center were, therefore, excluded from this study. Tumor volume was calculated on preoperative MRI by ellipsoid approximation from maximum cross-sectional diameters. Postoperative clinical outcomes measured consisted of functional status, as measured by Karnofsky Performance Status (KPS) score, at initial postoperative and last followup, timing of recurrence, and overall survival. The study was approved by the medical center's Institutional Review Board and informed consent was waived.

\section{Pathological review}

Tumor specimens were reviewed by experienced neuropathologists for tumor grade based on WHO guidelines. Histologic features including presence of brain invasion and mitotic index were assessed. Mitoses were counted per 10 high-power field (HPF) in the area of most prominent mitotic activity. Brain invasion was determined by presence of irregular tumor projections into brain parenchyma or separate islands of tumor surrounded by brain parenchyma without an intervening layer of leptomeninges. For some cases, Ki67 proliferation index was determined at time of initial pathologic review.

\section{Targeted next-generation genomic sequencing}

DNA extraction from FFPE tissues was performed using Maxwell FFPE Plus DNA Purification Kit (Promega). Approximately $50 \mu \mathrm{m}$ thickness of tissue was used for each extraction. DNA tissue libraries were generated using the Ion AmpliSeq Oncomine Comprehensive research panel versions 2.0 and 3.0 as described previously (https://www.thermofisher.com/ us/en/home/clinical/preclinical-companion-diagnosticdevelopment/oncomine-oncology/oncomine-cancerresearch-panel-workflow.html) [51]. Sequencing data analysis was performed using Torrent Suite (versions 5.6.0. and 5.8.0.) and Ion Reporter (versions 5.2, 5.6, and 5.8).

\section{Statistics}

Comparisons of matched primary tumor and first recurrence were performed using McNemar's test for paired proportions and Wilcoxon signed-rank tests, as appropriate. Multivariate stepwise regression analyses were performed on tumor features including tumor volume and mitotic index. Preoperative clinical characteristics and treatment features were entered as covariates. Further, multivariate Cox regression analyses on progression-free survival (PFS) and overall survival (OS) were similarly performed. Survival estimates were compared through the Kaplan-Meier method and evaluated with log-rank tests. Results of multivariate analyses were summarized using beta-coefficients (B) or hazard ratios (HR) and 95\% confidence intervals (CI) as appropriate. Analyses were performed using a standard statistical package SPSS (v22.0, IBM, Armonk, NY) and a $p$-value $<0.05$ was considered statistically significant.

\section{CONCLUSIONS}

Within a large panel of clinically actionable driver mutations, matched primary and recurrent meningiomas exhibited similar genomic alterations, most commonly in NF2 and POLE genes. NF2 mutational status was associated with tumor features including size, vasogenic edema, and mitotic proliferation. These findings help to inform how targeted precision therapies may play a role in the treatment of recurrent meningiomas and identify patients at risk for poorer clinical outcomes.

\section{CONFLICTS OF INTEREST}

The authors declare no conflicts of interest. 


\section{REFERENCES}

1. Yang SY, Park CK, Park SH, Kim DG, Chung YS, Jung HW. Atypical and anaplastic meningiomas: prognostic implications of clinicopathological features. J Neurol Neurosurg Psychiatry. 2008; 79:574-80. https://doi. org/10.1136/jnnp.2007.121582. [PubMed]

2. Goyal LK, Suh JH, Mohan DS, Prayson RA, Lee J, Barnett GH. Local control and overall survival in atypical meningioma: a retrospective study. Int J Radiat Oncol Biol Phys. 2000; 46:57-61. https://doi.org/10.1016/S03603016(99)00349-1. [PubMed]

3. Jääskeläinen J, Haltia M, Servo A. Atypical and anaplastic meningiomas: radiology, surgery, radiotherapy, and outcome. Surg Neurol. 1986; 25:233-42. https://doi. org/10.1016/0090-3019(86)90233-8. [PubMed]

4. Dziuk TW, Woo S, Butler EB, Thornby J, Grossman R, Dennis WS, Lu H, Carpenter LS, Chiu JK. Malignant meningioma: an indication for initial aggressive surgery and adjuvant radiotherapy. J Neurooncol. 1998; 37:177-88. https://doi.org/10.1023/A:1005853720926. [PubMed]

5. Park SH, Won J, Kim SI, Lee Y, Park CK, Kim SK, Choi SH. Molecular Testing of Brain Tumor. J Pathol Transl Med. 2017; 51:205-23. https://doi.org/10.4132/jptm.2017.03.08. [PubMed]

6. Aldape K, Nejad R, Louis DN, Zadeh G. Integrating molecular markers into the World Health Organization classification of CNS tumors: a survey of the neurooncology community. Neuro Oncol. 2017; 19:336-44. https://doi.org/10.1093/neuonc/now181. [PubMed]

7. Aghi MK, Carter BS, Cosgrove GR, Ojemann RG, AminHanjani S, Martuza RL, Curry WT Jr, Barker FG 2nd. Long-term recurrence rates of atypical meningiomas after gross total resection with or without postoperative adjuvant radiation. Neurosurgery. 2009; 64:56-60. https://doi. org/10.1227/01.NEU.0000330399.55586.63. [PubMed]

8. Goldsmith BJ, Wara WM, Wilson CB, Larson DA. Postoperative irradiation for subtotally resected meningiomas. A retrospective analysis of 140 patients treated from 1967 to 1990. J Neurosurg. 1994; 80:195-201. https://doi.org/10.3171/jns.1994.80.2.0195. [PubMed]

9. Hug EB, Devries A, Thornton AF, Munzenride JE, Pardo FS, Hedley-Whyte ET, Bussiere MR, Ojemann R. Management of atypical and malignant meningiomas: role of high-dose, 3D-conformal radiation therapy. J Neurooncol. 2000; 48:151-60. https://doi.org/10.1023/A:1006434124794. [PubMed]

10. Jenkinson MD, Javadpour M, Haylock BJ, Young B, Gillard H, Vinten J, Bulbeck H, Das K, Farrell M, Looby S, Hickey H, Preusser M, Mallucci CL, et al. The ROAM/EORTC1308 trial: Radiation versus Observation following surgical resection of Atypical Meningioma: study protocol for a randomised controlled trial. Trials. 2015; 16:519. https:// doi.org/10.1186/s13063-015-1040-3. [PubMed]
11. Brastianos PK, Galanis E, Butowski N, Chan JW, Dunn IF, Goldbrunner R, Herold-Mende C, Ippen FM, Mawrin C, McDermott MW, Sloan A, Snyder J, Tabatabai G, et al, and International Consortium on Meningiomas. Advances in multidisciplinary therapy for meningiomas. Neuro Oncol. 2019; 21:i18-31. https://doi.org/10.1093/neuonc/noy136. [PubMed]

12. Petrilli AM, Fernández-Valle C. Role of Merlin/NF2 inactivation in tumor biology. Oncogene. 2016; 35:537-48. https://doi.org/10.1038/onc.2015.125. [PubMed]

13. Preusser $\mathrm{M}$, Brastianos $\mathrm{PK}$, Mawrin C. Advances in meningioma genetics: novel therapeutic opportunities. Nat Rev Neurol. 2018; 14:106-15.https://doi.org/10.1038/ nrneurol.2017.168. [PubMed]

14. Reuss DE, Piro RM, Jones DT, Simon M, Ketter R, Kool M, Becker A, Sahm F, Pusch S, Meyer J, Hagenlocher C, Schweizer L, Capper D, et al. Secretory meningiomas are defined by combined KLF4 K409Q and TRAF7 mutations. Acta Neuropathol. 2013; 125:351-58. https:// doi.org/10.1007/s00401-013-1093-x. [PubMed]

15. Juratli TA, McCabe D, Nayyar N, Williams EA, Silverman IM, Tummala SS, Fink AL, Baig A, Martinez-Lage M, Selig MK, Bihun IV, Shankar GM, Penson T, et al. DMD genomic deletions characterize a subset of progressive/higher-grade meningiomas with poor outcome. Acta Neuropathol. 2018; 136:779-92. https://doi.org/10.1007/s00401-018-1899-7. [PubMed]

16. Yuzawa S, Nishihara H, Tanaka S. Genetic landscape of meningioma. Brain Tumor Pathol. 2016; 33:237-47. https:// doi.org/10.1007/s10014-016-0271-7. [PubMed]

17. Bi WL, Greenwald NF, Abedalthagafi M, Wala J, Gibson WJ, Agarwalla PK, Horowitz P, Schumacher SE, Esaulova E, Mei Y, Chevalier A, Ducar M, Thorner AR, et al. Genomic landscape of high-grade meningiomas. NPJ Genom Med. 2017; 2:15. https://doi.org/10.1038/s41525017-0014-7. [PubMed]

18. Ruttledge MH, Sarrazin J, Rangaratnam S, Phelan CM, Twist E, Merel P, Delattre O, Thomas G, Nordenskjöld M, Collins VP, Dumanski JP, Rouleau GA. Evidence for the complete inactivation of the NF2 gene in the majority of sporadic meningiomas. Nat Genet. 1994; 6:180-84. https:// doi.org/10.1038/ng0294-180. [PubMed]

19. Sahm F, Schrimpf D, Stichel D, Jones DT, Hielscher T, Schefzyk S, Okonechnikov K, Koelsche C, Reuss DE, Capper D, Sturm D, Wirsching HG, Berghoff AS, et al. DNA methylation-based classification and grading system for meningioma: a multicentre, retrospective analysis. Lancet Oncol. 2017; 18:682-94. https://doi.org/10.1016/ S1470-2045(17)30155-9. [PubMed]

20. Cimino PJ, Yoda RA, Wirsching HG, Warrick JI, Dorschner MO, Ferreira M. Genomic profiling of anaplastic meningioma identifies recurr ent genetic alterations with relevance to lower-grade meningioma. Neuropathol Appl Neurobiol. 2019; 45:179-182. https://doi.org/10.1111/ nan.12487. [PubMed] 
21. Li Q, Zhao F, Ju Y. Germline mutation of CHEK2 in neurofibromatosis 1 and 2: two case reports. Medicine (Baltimore). 2018; 97:e10894. https://doi.org/10.1097/ MD.0000000000010894. [PubMed]

22. McNulty SN, Schwetye K, Goldstein M, Carter J, Schmidt RE, Ansstas G, Tsien CI, Kim AH, Dahiya S. Analysis of point mutations and copy number variation in Grade II and III meningioma. Exp Mol Pathol. 2018; 105:328-33. https:// doi.org/10.1016/j.yexmp.2018.10.007. [PubMed]

23. Brastianos PK, Horowitz PM, Santagata S, Jones RT, McKenna A, Getz G, Ligon KL, Palescandolo E, Van Hummelen P, Ducar MD, Raza A, Sunkavalli A, Macconaill LE, et al. Genomic sequencing of meningiomas identifies oncogenic SMO and AKT1 mutations. Nat Genet. 2013; 45:285-89. https://doi.org/10.1038/ng.2526. [PubMed]

24. Abedalthagafi M, Bi WL, Aizer AA, Merrill PH, Brewster R, Agarwalla PK, Listewnik ML, Dias-Santagata D, Thorner AR, Van Hummelen P, Brastianos PK, Reardon DA, Wen PY, et al. Oncogenic PI3K mutations are as common as AKT1 and SMO mutations in meningioma. Neuro Oncol. 2016; 18:649-55. https://doi.org/10.1093/ neuonc/nov316. [PubMed]

25. Strickland MR, Gill CM, Nayyar N, D'Andrea MR, Thiede C, Juratli TA, Schackert G, Borger DR, Santagata S, Frosch MP, Cahill DP, Brastianos PK, Barker FG 2nd. Targeted sequencing of SMO and AKT1 in anterior skull base meningiomas. J Neurosurg. 2017; 127:438-44. https://doi. org/10.3171/2016.8.JNS161076. [PubMed]

26. Abedalthagafi MS, Bi WL, Merrill PH, Gibson WJ, Rose MF, Du Z, Francis JM, Du R, Dunn IF, Ligon AH, Beroukhim R, Santagata S. ARID1A and TERT promoter mutations in dedifferentiated meningioma. Cancer Genet. 2015; 208:345-50. https://doi.org/10.1016/j. cancergen.2015.03.005. [PubMed]

27. Juratli TA, Brastianos PK, Cahill DP. TERT Alterations in progressive treatment-resistant meningiomas. Neurosurgery. 2018; 65:66-68. https://doi.org/10.1093/neuros/nyy154. [PubMed]

28. Sahm F, Schrimpf D, Olar A, Koelsche C, Reuss D, Bissel J, Kratz A, Capper D, Schefzyk S, Hielscher T, Wang Q, Sulman EP, Adeberg S, et al. TERT Promoter Mutations and Risk of Recurrence in Meningioma. J Natl Cancer Inst. 2015; 108. https://doi.org/10.1093/jnci/djv377. [PubMed]

29. Biczok A, Kraus T, Suchorska B, Terpolilli NA, Thorsteinsdottir J, Giese A, Tonn JC, Schichor C. TERT promoter mutation is associated with worse prognosis in WHO grade II and III meningiomas. J Neurooncol. 2018; 139:671-78. https://doi.org/10.1007/s11060-018-2912-7. [PubMed]

30. Peyre M, Gauchotte G, Giry M, Froehlich S, Pallud J, Graillon T, Bielle F, Cazals-Hatem D, Varlet P, Figarella-Branger D, Loiseau H, Kalamarides M. De novo and secondary anaplastic meningiomas: a study of clinical and histomolecular prognostic factors. Neuro Oncol. 2018; 20:1113-21. https:// doi.org/10.1093/neuonc/nox231. [ubMed]
31. Spiegl-Kreinecker S, Lötsch D, Neumayer K, Kastler L, Gojo J, Pirker C, Pichler J, Weis S, Kumar R, Webersinke G, Gruber A, Berger W. TERT promoter mutations are associated with poor prognosis and cell immortalization in meningioma. Neuro Oncol. 2018; 20:1584-93. https://doi. org/10.1093/neuonc/noy104. [PubMed]

32. Goutagny S, Nault JC, Mallet M, Henin D, Rossi JZ, Kalamarides M. High incidence of activating TERT promoter mutations in meningiomas undergoing malignant progression. Brain Pathol. 2014; 24:184-89. https://doi. org/10.1111/bpa.12110. [PubMed]

33. Clark VE, Erson-Omay EZ, Serin A, Yin J, Cotney J, Ozduman K, Avşar T, Li J, Murray PB, Henegariu O, Yilmaz $\mathrm{S}$, Günel JM, Carrión-Grant G, et al. Genomic analysis of non-NF2 meningiomas reveals mutations in TRAF7, KLF4, AKT1, and SMO. Science. 2013; 339:1077-80. https://doi. org/10.1126/science.1233009. [PubMed]

34. Harmanci AS, Youngblood MW, Clark VE, Coşkun S, Henegariu O, Duran D, Erson-Omay EZ, Kaulen LD, Lee TI, Abraham BJ, Simon M, Krischek B, Timmer M, et al. Integrated genomic analyses of de novo pathways underlying atypical meningiomas. Nat Commun. 2017; 8:14433. https://doi.org/10.1038/ncomms14433. [PubMed]

35. Bi WL, Abedalthagafi M, Horowitz P, Agarwalla PK, Mei Y, Aizer AA, Brewster R, Dunn GP, Al-Mefty O, Alexander BM, Santagata S, Beroukhim R, Dunn IF. Genomic landscape of intracranial meningiomas. J Neurosurg. 2016; 125:525-35. https://doi.org/10.3171/2015.6.JNS15591. [PubMed]

36. Williams S, Juratli T, Castro B, Lazaro T, Gill C, Nayyar N, Strickland M, Babinski M, Johnstone S, Frosch M, Silverman I, Ely H, Kaplan A, et al. Genomic Analysis of Posterior Fossa Meningioma Demonstrates Frequent AKT1 E17K Mutations in Foramen Magnum Meningiomas. J Neurol Surg B Skull Base. 2019. [Epub Ahead of Print]. https://doi.org/10.1055/s-0038-1676821.

37. Morimoto M, Yoshioka Y, Shiomi H, Isohashi F, Konishi K, Kotsuma T, Fukuda S, Kagawa N, Kinoshita M, Hashimoto N, Yoshimine T, Koizumi M. Significance of tumor volume related to peritumoral edema in intracranial meningioma treated with extreme hypofractionated stereotactic radiation therapy in three to five fractions. Jpn J Clin Oncol. 2011; 41:609-16. https://doi.org/10.1093/jjco/hyr022. [PubMed]

38. Trofatter JA, MacCollin MM, Rutter JL, Murrell JR, Duyao MP, Parry DM, Eldridge R, Kley N, Menon AG, Pulaski $\mathrm{K}$, Haase VH. A novel moesin-, ezrin-, radixin-like gene is a candidate for the neurofibromatosis 2 tumor suppressor. Cell. 1993; 72:791-800. https://doi.org/10.1016/0092$\underline{\text { 8674(93)90406-G. [PubMed] }}$

39. Rouleau GA, Merel P, Lutchman M, Sanson M, Zucman J, Marineau C, Hoang-Xuan K, Demczuk S, Desmaze C, Plougastel B, Pulst SM, Lenoir G, Bijlsma E, et al. Alteration in a new gene encoding a putative membrane-organizing protein causes neuro-fibromatosis type 2. Nature. 1993; 363:515-21. https://doi.org/10.1038/363515a0. [ [PubMed] 
40. Okada T, Lopez-Lago M, Giancotti FG. Merlin/NF-2 mediates contact inhibition of growth by suppressing recruitment of Rac to the plasma membrane. J Cell Biol. 2005; 171:361-71. https://doi.org/10.1083/jcb.200503165. [PubMed]

41. Kaempchen K, Mielke K, Utermark T, Langmesser S, Hanemann CO. Upregulation of the Rac1/JNK signaling pathway in primary human schwannoma cells. Hum Mol Genet. 2003; 12:1211-21. https://doi.org/10.1093/hmg/ ddg146. [PubMed]

42. Rong R, Tang X, Gutmann DH, Ye K. Neurofibromatosis 2 (NF2) tumor suppressor merlin inhibits phosphatidylinositol 3-kinase through binding to PIKE-L. Proc Natl Acad Sci USA. 2004; 101:18200-05. https://doi.org/10.1073/ pnas.0405971102. [PubMed]

43. Jin H, Sperka T, Herrlich P, Morrison H. Tumorigenic transformation by CPI-17 through inhibition of a merlin phosphatase. Nature. 2006; 442:576-79. https://doi. org/10.1038/nature04856. [PubMed]

44. Kros J, de Greve K, van Tilborg A, Hop W, Pieterman H, Avezaat C, Lekanne Dit Deprez R, Zwarthoff E. NF2 status of meningiomas is associated with tumour localization and histology. J Pathol. 2001; 194:367-72. https://doi. org/10.1002/path.909. [PubMed]

45. Wrobel G, Roerig P, Kokocinski F, Neben K, Hahn M, Reifenberger G, Lichter P. Microarray-based gene expression profiling of benign, atypical and anaplastic meningiomas identifies novel genes associated with meningioma progression. Int J Cancer. 2005; 114:249-56. https://doi.org/10.1002/ijc.20733. [PubMed]

46. Dunn IF, Du Z, Touat M, Sisti MB, Wen PY, Umeton R, Dubuc AM, Ducar M, Canoll PD, Severson E, Elvin JA,
Ramkissoon SH, Lin JR, et al. Mismatch repair deficiency in high-grade meningioma: a rare but recurrent event associated with dramatic immune activation and clinical response to PD-1 blockade. JCO Precis Oncol. 2018; 2018:1-12. https://doi.org/10.1200/PO.18.00190. [PubMed]

47. Stenzinger A, Pfarr N, Endris V, Penzel R, Jansen L, Wolf T, Herpel E, Warth A, Klauschen F, Kloor M, Roth W, Bläker H, Chang-Claude J, et al. Mutations in POLE and survival of colorectal cancer patients - link to disease stage and treatment. Cancer Med. 2014; 3:1527-38. https://doi. org/10.1002/cam4.305. [PubMed]

48. Loewenstern J, Aggarwal A, Pain M, Barthélemy E, Costa A, Bederson J, Shrivastava RK. Peritumoral edema relative to meningioma size predicts functional outcomes after resection in older patients. Operative Neurosurgery. 2019; 16:281-291. https://doi.org/10.1093/ons/opy107/5001333.

49. Hammouche S, Clark S, Wong AH, Eldridge P, Farah JO. Long-term survival analysis of atypical meningiomas: survival rates, prognostic factors, operative and radiotherapy treatment. Acta Neurochir (Wien). 2014; 156:1475-81. https://doi.org/10.1007/s00701-014-2156-z. [PubMed]

50. Perry A, Banerjee R, Lohse CM, Kleinschmidt-DeMasters BK, Scheithauer BW. A role for chromosome 9p21 deletions in the malignant progression of meningiomas and the prognosis of anaplastic meningiomas. Brain Pathol. 2002; 12:183-90. [PubMed]

51. Pain M, Wang H, Lee E, Strahl M, Hamou W, Sebra R, Zhu J, Yong RL. Treatment-associated TP53 DNAbinding domain missense mutations in the pathogenesis of secondary gliosarcoma. Oncotarget. 2018; 9:2603-2621. https://doi.org/10.18632/oncotarget.23517. [PubMed] 